\title{
A ORGANIZAÇÃO MUNDIAL DO COMÉRCIO E OS DIREITOS HUMANOS: UMA RELAÇÃO POSSÍVEL?
}

THE WORLD TRADE ORGANIZATION AND HUMAN RIGHTS: A RELATIONSHIP POSSIBLE?

\author{
Rogério Taiar* \\ Camilla Capucio**
}

\begin{abstract}
Resumo:
Este trabalho visa explorar as possibilidades de relação e complementariedade entre a formulação e aplicação das regras do comércio internacional e os direitos humanos, através da problematização sobre o papel dos direitos humanos na Organização Mundial do Comércio. Essa relação é abordada em sua perspectiva conceitual, seguida da breve análise das dificuldades práticas da ponderação entre as esferas. Partindo-se do posicionamento do Órgão de Solução de controvérsia nesta seara, explicitamos brevemente desdobramentos desta perspectiva em temas como os direitos trabalhistas e o dumping social, a saude pública e os direitos de propriedade intelectual, a proteção do meio ambiente, e, por fim, a transparência e governança democrática na $\mathrm{OMC}$.
Palavras-chave: Organização Mundial do Comércio (OMC). Comércio Internacional. Questões não-comerciais. Direitos Humanos. Interpretação Humanística.

\begin{abstract}
:
This paper aims to explore the possibilities of interaction and complementarity between the formulation and implementation of international trade rules and human rights, by problematizing the role of human rights in the World Trade Organization. This interaction is aproached in a conceptual perspective, followed by a brief analysis of the practical difficulties arising from the balancing of the two areas. Starting with the position of the Dispute Settlement Body, will be briefly explained the developments of this perspective on issues like labor rights and "social dumping", public health and intellectual property rights, the protection of the environment, and finally, transparency and democratic governance in the WTO.
\end{abstract}

Keywords: World Trade Organization (WTO). International Trade. Non-Trade Isues. Human Rights. Humanistic Interpretation.

\footnotetext{
Doutor em Direitos Humanos pela Faculdade de Direito da Universidade de São Paulo. Professor do Curso de Especialização Lato Sensu em Direito Internacional Público e Direito das Relações Internacionais da Escola Superior de Advocacia da Ordem dos Advogados do Brasil - Secção de São Paulo. Professor de Direito Internacional Público e de Teoria das Relações Internacionais dos Cursos de Graduação em Direito e de Relações Internacionais da Universidade Paulista (UNIP).

* Mestre em Direito Internacional pela Faculdade de Direito da Universidade Federal de Minas Gerais. Pesquisadora do Núcleo de Estudos em Tribunais Internacionais (NETI-USP) e do Centro de Estudos sobre o Brasil e a Organização Mundial do Comércio (CEB-OMC). Advogada e Professora.
} 


\section{Introdução}

Há aparentemente uma longínqua distância entre o comércio internacional e os direitos humanos. A Organização Mundial do Comércio (OMC), principal foro de negociações econômicas e de resolução de controvérsias entre os atores do sistema multilateral de comércio, à primeira vista suscita desinteresse e críticas por parte dos defensores dos direitos humanos.

Entretanto, em uma era na qual dualismos estanques são cada vez mais insuficientes para explicar as complexidades da realidade fática e jurídica, busca-se contemporaneamente encontrar uma relação equilibrada entre esferas anteriormente interpretadas como antagônicas. É nesse contexto que surge a discussão sobre a relação entre os direitos humanos e o comércio internacional, e a colocação dos direitos humanos na Organização Mundial do Comércio.

As relações entre o sistema multilateral de comércio e questões nãoeconômicas são uma das questões teóricas mais complexas nas relações internacionais. As interações conceituais e perplexidades práticas entre as políticas comerciais, a solução de controvérsias e a interpretação do conjunto de regras da OMC com o respeito e a valorização dos direitos humanos se desdobram em diversas possíveis facetas, que passam a ser brevemente explicitadas nesse trabalho.

2. Uma abordagem do comércio internacional "baseada nos direitos humanos": conteúdo, fundamentos e possibilidades

A Declaração e Programa de Viena sobre os Direitos Humanos de 1993 consolida e explicita a compreensão dos direitos humanos como "universais, indivisíveis, interdependentes e interelacionados" " Nesse mesmo documento também está destacada a necessidade de atuação não somente dos Estados, mas também das Organizações Internacionais, para a criação de condições favoráveis a níveis nacional, regional e internacional para garantir o gozo completo e efetivo dos direitos humanos. ${ }^{2}$

\footnotetext{
1 "All human rights are universal, indivisible and interdependent and interrelated. The international community must treat human rights globally in a fair and equal manner, on the same footing, and with the same emphasis. While the significance of national and regional particularities and various historical, cultural and religious backgrounds must be borne in mind, it is the duty of States, regardless of their political, economic and cultural systems, to promote and protect all human rights and fundamental freedoms". Ponto 5 da Declaração, versão em inglês disponivel em: <http://www.unhchr.ch/huridocda/huridoca.nsf/(symbol)/A.CONF.157.23.En?OpenDocument>.

2 "There is a need for States and international organizations, in cooperation with non-governmental organizations, to create favourable conditions at the national, regional and international levels to ensure the full and effective enjoyment of human rights." Ponto 13 da Declaração, versão em inglês disponível em: $<$ http://www.unhchr.ch/huridocda/huridoca.nsf/(symbol)/A.CONF.157.23.En?OpenDocument>.
} 
Entretanto, os principais órgãos de Direitos Humanos da ONU tendiam até recentemente a ignorar a relevância do sistema GATT-OMC e do comércio internacional como forma de garantir a proteção aos direitos humanos, ocasionalmente inclusive ressaltando uma suposta oposição e antagonismo. A OMC era então entendida como um "verdadeiro pesadelo" para o respeito aos direitos humanos nos países em desenvolvimento. ${ }^{3}$ Naquela abordagem, ignorava-se também o papel do comércio internacional na interdependência prática entre o exercício subjetivo de grande parte dos direitos humanos e o acesso a bens e serviços escassos, bem como na necessidade de recursos financeiros para a garantia coletiva desses direitos humanos.

Em 1999, o "Pacto Global"4 lançado pelo então Secretário Geral da ONU Kofi Annan, chama a atenção da comunidade empresarial internacional para o apoio e respeito à proteção de valores fundamentais e direitos humanos em suas práticas empresariais. A iniciativa inaugura a percepção da função dos atores econômicos na implementação dos direitos humanos, bem como da necessidade de um "Pacto global complementar" entre a ONU, suas agências especializadas e outras organizações internacionais como a Organização Mundial do Comércio, com o objetivo de integrar os direitos humanos à prática das organizações intergovernamentais. ${ }^{5}$

Recentemente observou-se, portanto, uma mudança de posicionamento da ONU no que tange à interdependência entre as temáticas do comércio internacional e dos direitos humanos. A partir de 2001, o Alto Comissariado das Nações Unidas para os Direitos Humanos publicou uma série de paradigmáticos relatórios, analisando as dimensões de direitos humanos nos principais Acordos da OMC. ${ }^{6}$ Em conjunto, os documentos propõem uma abordagem do comércio internacional baseada nos direitos humanos.

\footnotetext{
Globalization and its Impact on the Full Enjoyment of Human Rights, E/CN.4/Sub.2/2000/13, 15 de Junho de 2000, disponivel em: <http://www.unhchr.ch/Huridocda/Huridoca.nsf/(Symbol)/E.Cn.4.Sub.2.2000.13.En?Opendocument>. Parágrafo 15: "Furthermore, even its purely trade and commerce activities have serious human rights implications. This is compounded by the fact that the founding instruments of WTO make scant (indeed only oblique) reference to the principles of human rights. The net result is that for certain sectors of humanity particularly the developing countries of the South - the WTO is a veritable nightmare. The fact that women were largely excluded from the WTO decision-making structures, and that the rules evolved by WTO are largely gender-insensitive, means that women as a group stand to gain little from this organization"

4 Para maiores informações sobre o pacto global: <http://www.pactoglobal.org.br/pactoGlobal.aspx >.

5 PETERSMANN, Ernst-Ulrich. Time for a United Nations 'Global Compact' for Integrating Human Rights into the Law of Worldwide Organizations: Lessons from European Integration. European Journal of International Law, June 2002.

6 The impact of the Agreement on Trade-Related Aspects of Intellectual Property Rights on Human Rights, E/ CN.4/Sub.2/2001/13, 27 de Junho de 2001. Disponivel em: <http://www.unhchr.ch/Huridocda/Huridoca.nsf/ Symbol/E.CN.4.Sub.2.2001.13.En?Opendocument>; Globalization and its Impact on the Full Enjoyment of Human Rights, E/CN.4/2002/54, 15 de Janeiro de 2002. Disponivel em: <http://www.unhchr.ch/huridocda/ huridoca.nsf/(Symbol)/E.CN.4.2002.54.En?Opendocument>; Liberalization of Trade in Services and Human Rights, E/CN.4/Sub.2/2002/9, 25 de Junho de 2002. Disponivel em: <http://www.unhchr.ch/Huridocda/ Huridoca.nsf/0/32f8a4ad6cc5f9b9c1256c05002a87f8?Opendocument>; Human Rights, Trade and Investment, E/CN.4/Sub.2/2003/9, 18 de Junho de 2003. Disponível em: <http://www.unhchr.ch/Huridocda/
} 
Essa nova abordagem (a) estabelece a promoção e proteção dos direitos humanos como objetivos precípuos do comércio; (b) examina o efeito da liberalização do comércio sob indivíduos e determina que as regras do comércio internacional levem em consideração o direito de todos os indivíduos, em especial aqueles indivíduos e grupos vulneráveis; (c) enfatiza o papel do Estado no processo de liberalização - não somente como negociadores das regras de comércio e emanadores de políticas comerciais, mas também como garantidores primários dos direitos humanos; (d) busca consistência entre a progressiva liberalização do comércio e a progressiva realização dos direitos humanos; (e) requer um exame constante do impacto da liberalização do comércio no gozo dos direitos humanos e (d) promove cooperação internacional para a realização dos direitos humanos e liberdades no contexto da liberalização do comércio. ${ }^{7}$

No contexto da abordagem de direitos humanos advogada pelo Alto Comissariado das Nações Unidas, não somente os Estados, mas também as Organizações Internacionais possuem obrigações de respeitar, de proteger e de promover os direitos humanos. As instituições de Bretton Woods, em especial, devem tomar medidas de assistência aos governos para que estes atuem de maneira compatível com suas obrigações de direitos humanos. Nesse sentido, a OMC não pode se escusar de suas obrigações, tendo em vista o impacto direto que suas regras e decisões têm na vida e nos direitos humanos dos indivíduos, e a busca por um desenvolvimento humano sustentável como finalidade última de todos os instrumentos de Direito Internacional. ${ }^{8}$

Os Relatórios em seu conjunto destacam que embora os conflitos entre regras da OMC frequentemente de caráter flexível - e normas de direitos humanos pareçam improváveis em nível principiológico, existem potenciais tensões entre regras "existenciais" de direitos humanos e regras "instrumentais" da OMC, que urgem por interpretações mutuamente coerentes. ${ }^{9}$ Observa-se, ademais, que provisões nos Acordos da OMC que

Huridoca.nsf/0/32f8a4ad6cc5f9b9c1256c05002a87f8?Opendocument>; Globalization and its Impact on the Full Enjoyment of Human Rights: Final Report, E/CN.4/Sub.2/2003/14, 25 de Junho de 2003. Disponivel em: <http://www.unhchr.ch/Huridocda/Huridoca.nsf/(Symbol)/E.CN.4.Sub.2.2003.14.En?Opendocument>; Analytical Study of the High Commissioner for Human Rights on the Fundamental Principle of NonDiscrimination in the Context of Globalization, E/CN.4/2004/40, 15 de Janeiro de 2004. Disponivel em: $<$ http://www.unhchr.ch/Huridocda/Huridoca.nsf/(Symbol)/E.CN.4.2004.40.En?Opendocument>; Report by the Special rapporteur Paul Hunt on his Mission to the WTO, E/CN.4/2004/49/Add.1, 1 de Março de 2004. Disponivel em: <http://www.unhchr.ch/Huridocda/Huridoca.nsf/0/893elcddedb9014cc1256e670046d0fa/\$FI $\mathrm{LE} / \mathrm{G} 0411393 . \mathrm{doc}>$; Mainstreaming the right to development into international trade law and policy at the World Trade Organization, E/CN.4/Sub.2/2004/17, 9 de Junho de 2004. Disponivel em: <http://daccess-ddsny.un.org/doc/UNDOC/GEN/G04/145/22/PDF/G0414522.pdf?OpenElement>.

7 Liberalization of Trade in Services and Human Rights, E/CN.4/Sub.2/2002/9, 25 de Junho de 2002. Disponível em: $<$ http://www.unhchr.ch/Huridocda/Huridoca.nsf/0/32f8a4ad6cc5f9b9c1256c05002a87f8?Opendocument>. p. 2.

8 Globalization and its Impact on the Full Enjoyment of Human Rights: Final Report, E/CN.4/ Sub.2/2003/14, 25 de Junho de 2003. Disponivel em: <http://www.unhchr.ch/Huridocda/Huridoca.nsf/ (Symbol)/E.CN.4.Sub.2.2003.14.En?Opendocument>. p. 14.

9 PETERSMANN, Enst-Ulrich. Reforming the World Trading System: legitimacy, efficiency and democratic 
explicitam um direito dos membros de regulamentar certa questão, com frequência correspondem a um dever dos Estados de promover tal regulamentação em respeito aos direitos humanos.

De maneira geral, o Alto Comissariado propõe que as normas de direitos humanos forneçam arcabouço jurídico para a proteção de dimensões sociais da liberalização do comércio como complementação de regras comerciais ${ }^{10}$ Não obstante tenham sido sugeridos a cooperação mútua entre órgãos de direitos humanos e organizações econômicas, bem como o reconhecimento da promoção dos direitos humanos como um dos objetivos da OMC, ${ }^{1 "}$ a inexistência de metodologia específica e sistemática para a o desenvolvimento prático dessa sinergia deixa espaço para ampla discussão doutrinária.

\section{Os Direitos Humanos na interpretação das regras da OMC}

A necessidade de incorporação de uma perspectiva de direitos humanos à sistemática institucional da OMC e à interpretação de suas regras têm como principal e persistente voz Ernst-Ulrich Petersmann, ex-Assessor Jurídico do GATT e da OMC. Há algumas décadas o autor explicita no denso conjunto de sua obra ${ }^{12}$ não somente a

governance. New York: Oxford University Press, 2005. p. 368-9.

10 Globalization and its Impact on the Full Enjoyment of Human Rights, E/CN.4/2002/54, 15 de Janeiro de 2002. Disponivel em: <http://www.unhchr.ch/huridocda/huridoca.nsf/(Symbol)/E.CN.4.2002.54.En?Opendocument>.

11 Analytical Study of the High Commissioner for Human Rights on the Fundamental Principle of NonDiscrimination in the Context of Globalization, E/CN.4/2004/40, 15 de Janeiro de 2004. Disponivel em: $<\mathrm{http} / / /$ www.unhchr.ch/Huridocda/Huridoca.nsf/(Symbol)/E.CN.4.2004.40.En?Opendocument>. p. 18-9.

12 Em uma lista meramente exemplificativa e não exaustiva, citamos algumas publicações relevantes do autor que abarcam a temática: E.-U. Petersmann, Constitutional Functions and Constitutional Problems of International Economic Law (1991), Ch. VII; Petersmann, 'National Constitutions, Foreign Trade Policy and European Community Law' 2 E.IL (1993) 1; Petersmann, 'National Constitutions and International Economic Law': in M. Hilf and E.-U. Petersmann (eds), National Constitutions and International Economic Law (1993) 3; Petersmann, 'Constitutional Principles Governing the EEC's Commercial Policy'. in M. Maresceau (ed.), The European Community's Commercial Policy after 1992: The Legal Dimension (1993) 21; Petersmann, 'Constitutionalism and International Organizations', 17 Northwestern J. In'l L. Bus. (1996) 398; Petersmann, "How to Constitutionalize the United Nations? Lessons from the "International Economic Law Revolution", in V. Götz. P. Selmer and R. Wolfrum (eds), Liber Amicorum G. Jaenicke (1998) 313; Petersmann, 'How to Constitutionalize International Law and Foreign Policy for the Benefit of Civil Society?', 20 Mich. J. Int'l L. (1999) 1; Petersmann, 'Legal, Economic and Political Objectives of National and International Competition Policies; Constitutional Functions of WTO "Linking Principles" for Trade and Competition', 34 New Eng. L. Rev. (1999) 145; Petersmann, 'Constitutionalism and International Adjudication: How to Constitutionalize the U.N. Dispute Settlement System?', 31 NYU J. In'1 L. \& Pol. (1999) 753; Petersmann, 'From "Negative" to Positive "Integration" in the WTO: Time for "Mainstreaming Human Rights" into WTO Law?', 37 CMLR (2000) 1363; Petersmann, 'The WTO Constitution and Human Rights', 3 JIEL (2000) 19; Petersmann, 'Human Rights and International Economic Law in the 21st Century', 4 JIEL (2001) 3; Petersmann, 'Time for Integrating Human Rights into the Law of Worldwide Organizations'. Jean Monnet Working Paper of New York University School of Law 7/01 (2001); Petersmann, 'European and International Constitutional Law: Time for Promoting "Cosmopolitan Democracy" in the WTO', in G. de Búrca and J. Scott (eds), The EU and the WTO (2001) 81; Petersmann, 'International Activities of the European Union and Sovereignty of Member States', in E. Cannizzaro (ed.), The European Union as an Actor in International Relations (2002) 
necessidade de incorporação de parâmetros de direitos humanos no entendimento do direito da OMC, mas também a necessidade de incorporação do direito ao livre comércio como um direito fundamental, objetivando o que ele denomina de "constitucionalização" da OMC.

Pettersman acredita que o reconhecimento explícito pela OMC das obrigações de direitos humanos como "contexto jurídico" relevante para a interpretação e aplicação de suas regras, rompendo com a atitude de diplomatas e órgãos da OMC em evitar posicionamentos oficiais sobre a proposta de uma abordagem do comércio internacional baseada nos direitos humanos poderia aumentar a legitimidade e aceitação democrática da instituição. ${ }^{13} \mathrm{O}$ autor apresenta diversas razões para a incorporação dos direitos humanos como contexto jurídico relevante para a OMC, classificando-as em razões jurídicas, políticas e econômicas.

Como principal razão jurídica, destaca o art. 3:2 do Entendimento do Órgão de Solução de Controvérsias: "Os membros reconhecem que este serve para preservar os direitos e obrigações dos membros sob os acordos cobertos, e para clarificar as provisões existentes nesses acordos, em concordância com regras costumeiras de interpretação do Direito Internacional",

De acordo com a própria jurisprudência da OMC, e em aplicação ao art. 31:1 e 31:3(c) da Convenção de Viena do Direito dos Tratados, tal interpretação deve incluir "quaisquer regras relevantes de direito internacional aplicáveis nas relações entre as partes" Considerando a vinculação e obrigatoriedade das principais regras protetivas dos direitos humanos em relação a todos os Estados membros da $\mathrm{OMC}$, derivada de seu caráter erga omnes, tais normas devem ser consideradas na interpretação do direito da OMC.

Entretanto, salienta o autor, nessa vinculação necessária do direito da OMC a uma interpretação que leve em conta normas de direitos humanos, se apresentam diversas questões jurídicas delicadas perante o Órgão de Solução de Controvérsias. Na aplicação das regras da OMC, o OSC deve ponderar como e em que limites poderiam levar em conta a jurisprudência e os comentários de órgãos especializados em direitos humanos, tendo em vista o constante risco de, em sua atividade interpretativa, adicionar

321; Petersmann, 'Human Rights in European and Global Integration Law: Principles for Constitutionalizing the World Economy', in A. von Bogdandy, P. Mavroidis and Y. Mény, European Integration and International Coordination: Festschrift für C. D. Ehlermann (2002) 383; Petersmann, 'Constitutionalism, International Law and "We the Peoples of the United Nations"', in H.-J. Cremer et al. (eds), Tradition und Weltoffenheit des Rechts: Festscrift für Helmut Steinberger (2002) 291; Petersmann, 'Economics and Human Rights', in F. Abbott and T. Cottier (eds), International Trade and Human Rights (2002, forthcoming). PETERSMANN, Ernst-Ulrich. Reforming the World Trading System: legitimacy, efficiency and democratic governance. New York: Oxford University Press, 2005. JOERGE, Christian; PETERSMANN, Ernst-Ulrich Constitutionalism, Multilevel Trade Governance And Social Regulation. London: Hart Publishing, 2007. DUPUY, Pierre-Marie; PETERSMANN, Ernst-Ulrich; FRANCIONI, Francesco. Human Rights in International Investment Law and Arbitration. New York: Oxford University Press, 2009.

13 PETERSMANN, Ernst-Ulrich. Reforming the World Trading System: legitimacy, efficiency and democratic governance. New York: Oxford University Press, 2005. p. 359. 
ou diminuir os direitos e obrigações previstos nos acordos, em violação ao art. 3:2 do Entendimento de Solução de Controvérsias. Nessa perspectiva, seria mais apropriado que os órgãos "políticos" da OMC, a exemplo das Conferências Ministeriais, determinem o relevante escopo das obrigações gerais de direitos humanos para a OMC.

Há também uma razão política apontada para a importância dos direitos humanos como contexto jurídico relevante para a OMC. A teoria utilitarista clássica, que busca a explicação para a liberalização do comércio internacional na possibilidade de aumentar o bem-estar de todos os membros através do comércio, parece não ser mais suficiente para garantir a legitimidade da OMC. A incorporação de uma abordagem baseada nos direitos humanos poderia, portanto, diminuir distorções na aplicação de muitas regras do sistema GATT-OMC, que na prática podem resultar em favorecimento de interesses dos produtores mais poderosos, ao deixar para a discricionariedade dos governos a preocupação com uma "distribuição justa" dos ganhos do comércio e ajuste social de problemas de competitividade. ${ }^{14}$

Petersmann apresenta, ainda, uma razão econômica para a importância dos direitos humanos como contexto jurídico relevante para a OMC. Nessa esteira, estudos do Programa das Nações Unidas para o Desenvolvimento demonstram que a proteção dos direitos humanos pode fazer dos cidadãos atores econômicos mais eficientes ${ }^{15}$. $\mathrm{O}$ autor defende a idéia de que o livre comércio é necessário para a criação de bem-estar econômico e gozo dos direitos humanos, assim como o respeito pelos direitos humanos e necessidades básicas dos indivíduos possibilitam uma "economia social de mercado" cuja coesão social e solidariedade é capaz de aumentar o crescimento econômico, de maneira complementar. O respeito aos direitos humanos é capaz, portanto, de aumentar a eficiência não somente da democracia, mas inclusive dos mercados econômicos.

Desse modo, continua Petersmann, o "direito ao livre comércio" e os principais direitos humanos estariam interelacionados e seriam interdependentes:

The globalization of human rights and of economic integration law offers mutually beneficial synergies: protection and enjoyment of human rights depend also on economic resources and on integration law opening markets, reducing discrimination and enabling a welfare-increasing division of labour.

Embora as convenções de direitos humanos da ONU ignorem o direito ao livre comércio, a União Européia se apresentaria como exemplo bem sucedido da

14 PETERSMANN, Ernst-Ulrich. Reforming the World Trading System: legitimacy, efficiency and democratic governance. New York: Oxford University Press, 2005. p. 364.

15 Programa das Nações Unidas Para o Desenvolvimento -UNDP. Human Development Report 2000: Human Rights and Human Development. Disponível no site: $<\mathrm{http}: / /$ hdr.undp.org/en/media/HDR_2000_EN.pdf $>$. 
incorporação do livre comércio como uma esfera de garantia e de liberdade dos indivíduos, inclusive através de uma interpretação consistente e complementar dos direitos humanos e direito da integração econômica pelos órgãos jurisdicionais.

Propõe, desse modo, que: "as in European integration law, human rights should be recognized in global integration law as empowering citizens, as constitutionally limiting national and international regulatory powers, and as requiring governments to protect and promote human rights in all policy areas across national frontiers"

Por fim, o autor propõe o processo de constitucionalização da Organização Mundial do Comércio, como forma de positivar tais direitos no ordenamento jurídico da organização, bem como de aumentar sua legitimidade e eficiência. Especial atenção deve ser dada à legitimidade "democrática" como sustentáculo de toda a Organização. Logo, o autor explicita:

in order to remain democratically acceptable, global integration law (e.g. in the WTO) must pursue not only 'economic efficiency' but also 'democratic legitimacy" and 'social justice' as defined by human rights.

Como principais dificuldades, entretanto, o autor destaca que as visões sobre o conteúdo dos direitos humanos diferem, e sua inclusão na pauta das negociações pode gerar ainda maiores dificuldades na conclusão da Rodada de Doha. A questão mais problemática se coloca no temor dos Estados menos desenvolvidos de que o "discurso dos direitos humanos" se materialize em protecionismo dos Estados desenvolvidos para minar suas vantagens comparativas, motivo pelo qual insistem que questões como os direitos trabalhistas sejam deixados para a Organização Internacional do Trabalho (OIT). Faz-se oportuno salientar a recomendação do Alto Comissariado das Nações Unidas, da "necessidade não somente de trazer uma perspectiva de direitos humanos para o comércio, mas também de uma perspectiva de comércio para os direitos humanos", em busca de um mútuo entendimento.

\section{Críticas a uma abordagem humanista do comércio internacional}

Em reação ao chamado por uma abordagem baseada nos direitos humanos para o comércio internacional, algumas críticas foram apresentadas. A principal e mais pertinente é a necessidade de delimitação do conteúdo das regras de direitos humanos a serem incorporadas na interpretação do direito da $\mathrm{OMC}$, bem como a discussão pelos membros da metodologia a ser utilizada para esse fim. Em crítica direcionada às propostas de Petersmann, Robert Howse destaca a necessidade de definir "in the name of whom and what the discourses of human rights, free trade, and constitutionalism are 
being invoked" 16 atentando para o freqüente uso de discursos de direitos humanos com o objetivo de perpetuar relações comerciais injustas entre os Estados.

Philip Alston, por sua vez, acusa Petersmann de apresentar a realização dos direitos humanos através da OMC como um simples desenvolvimento lógico de políticas já existentes, quando na verdade significaria uma ruptura radical das políticas do comércio internacional ${ }^{17}$ Questiona a aplicação prática do caráter erga omnes de algumas regras de direitos humanos, explicitado pela Corte Internacional de Justiça no caso Barcelona Traction, bem como a base jurídica da vinculação das Organizações Internacionais às normas protetivas de direitos humanos.

Alston critica também a controvertida proposta do processo de "constitucionalização" da OMC baseada nos direitos humanos, por ser o Acordo Constitutivo da OMC um tratado internacional que cria uma Organização Internacional com objetivos principais de liberalização e regulamentação do comércio internacional, a prescindir da constituição de uma comunidade política ou social. O autor destaca que desde sua origem, no sistema GATT, a OMC é uma instituição dominada pelo interesse de produtores, e na qual expectativas econômicas, sociais, culturais e políticas na maioria dos indivíduos não são, na prática, representadas.

Ademais, observa-se de modo geral certa relutância na OMC no que tange à incorporação das denominadas "preocupações não-comerciais"18 na agenda da organização. ${ }^{19}$ Oposicionamentotradicional daOMC tem sidoumavisãode "compartimentos estanques", pela qual a OMC é uma organização do comércio internacional, devendo deixar as preocupações de direitos humanos para os foruns competentes. ${ }^{20}$ Nos últimos anos, entretanto, a organização permitiu alguns desenvolvimentos em direção a uma maior "permeabilidade". embora a inclusão da proteção dos direitos humanos no sistema GATTOMC continue uma questão extremamente delicada.

16 HOWSE, Robert. Human Rights in the WTO: Whose Rights, What Humanity? Comment on Petersmann European Journal of International Law. Junho, 2002.

17 ALSTON, Philip. Resisting the Merger and Acquisition of Human Rights by Trade Law: a Reply to Petersmann. European Journal of International Law. Setembro, 2002.

18 Tradução nossa para a expressão na lingua inglesa "non-trade concerns"

19 ZAGEL, Gudrun Monika. WTO \& Human Rights: Examining Linkages and Suggesting Convergence. IDLO Voices of Development Jurists Paper Series, International Development Law Organization. v. 2. n. 2, 2005. p. 30. Disponivel no site http://www.worldtradelaw.net/articles/zagelhumanrights.pdf.

20 HOWSE, Robert. Economic, Social and Cultural Rights: Mainstreaming the Right to Development into International Trade Law and Policy at the World Trade Organization, E/CN.4/Sub.2/2004/17, 9 de Junho de 2004, disponível em: <http://daccess-dds-ny.un.org/doc/UNDOC/GEN/G04/145/22/PDF/G0414522.pdf?OpenElement:p. 9 e ss. 
5. Os direitos humanos entre a formação do direito da $\mathrm{OMC}$ e sua aplicação

A relação entre os direitos humanos e o comércio internacional pode se dar em dois momentos distintos: a discussão de sua incorporação na fase de negociações que resultam na elaboração das regras que compõem o direito da OMC e a sua consideração no momento de interpretação das regras já existentes, na aplicação prática das normas do comércio internacional. Se na primeira hipótese os Estados membros são diretamente responsáveis pela formação normativa e podem controlar o processo, na aplicação do direito da OMC os protagonistas são os árbitros dos Painéis e principalmente do Órgão de Apelação do sistema de solução de controvérsias da organização, a quem cabe a análise técnica de situações de conflito e interesses contrapostos.

Gabrielle Marceau destaca, em cuidadoso estudo sobre os direitos humanos no sistema de resolução de conflitos na OMC, que embora o direito da OMC seja um subsistema específico dentro do direito internacional, com regras e princípios próprios, suas provisões devem envolver e ser interpretadas em consistência com o direito internacional, inclusive com o direito internacional dos direitos humanos. ${ }^{21}$

De acordo com a Comissão de Direito Internacional da ONU, observase na atualidade o fenômeno de fragmentação do Direito Internacional, que resulta na criação de regras, princípios, sistemas jurídicos e práticas institucionais muitas vezes conflitantes e incompatíveis entre si. $^{22} \mathrm{O}$ direito da OMC enquadra-se com um dentre os vários complexos de regras funcionalmente delimitados dentro do Direito Internacional, denominados pela doutrina de "self-contained regimes" ${ }^{23}$ Embora a emergência de novos ramos possa originar problemas de coerência no direito internacional, a formulação de princípios próprios busca apaziguar a realidade fática objeto de sua regulamentação, e seu surgimento não é acidental, mas resposta a novos requisitos técnicos e funcionais que surgem na dinâmica da sociedade internacional.

A autora destaca, entretanto, que tal interpretação deve se dar em observância ao "domínio limitado" do mecanismo de solução de controvérsias da OMC, que por sua natureza própria tem seu mandato contido nos direitos e obrigações contidos nos Acordos da OMC, sendo vedada interpretação que na prática os amplie ou diminua. ${ }^{24}$

21 MARCEAU, Gabrielle. WTO Dispute Settlement and Human Rights. European Journal of International Law Setembro, 2002. p. 3.

22 KOSKENNIEMI, Marti. International Law Comission, $58^{\mathrm{a}}$ sessão. Fragmentation of International Law: Difficulties arrising from the Diversification and Expansion of International Law. Relatório do estudo analítico realizado pelo Grupo de Estudos da Comissão de Direito Internacional, 13 de abril de 2006, UN. Doc. A/CN.4/L.682. Disponivel em: <http://untreaty.un.org/ilc/texts/1_9.htm>.

23 SIMMA, Bruno. PULKOWSKI, Dirk. Of Planets and the Universe: Self-contained Regimes in International Law. European Journal of International Law, v. 17, n. 3, 2006.

24 MARCEAU, Gabrielle. WTO Dispute Settlement and Human Rights. European Journal of International Law Setembro, 2002. p. 14. 
Joost Pauwelyn, ${ }^{25}$ sobre esse ponto, argumenta que "the jurisdiction of WTO panels is limited. The applicable law before them is not", em entendimento pelo qual os membros presumidamente aceitaram o efeito vinculante e a aplicação direta do direito internacional às regras da OMC. Nos parece de fato coerente presumir, na constituição de um sistema internacional de resolução de conflitos, que normas de direito internacional, dentre elas normas protetivas dos direitos humanos, sejam utilizadas na colmatação de lacunas ou cláusulas flexíveis dos Acordos da OMC.

$\mathrm{O}$ art. $\mathrm{XX}^{26}$ do GATT se apresenta como um terreno especialmente permeável à proteção dos direitos humanos, abrindo espaço para derrogação de obrigações previstas no acordo pela adoção de medidas necessárias à "proteção da moralidade pública" "da saúde e vida das pessoas" e "dos animais e à preservação dos vegetais" Contudo, exatamente pela excepcionalidade dessas medidas e pelo caráter técnico do exame feito pelos árbitros nos Painéis e no Órgão de Apelação, pois inseridos em um foro comercial a prescindir de um órgão de direitos humanos, esta tem sido uma análise rígida, e para que a medida em questão configure uma exceção deve preencher estritamente os requisitos estabelecidos pelo caput do artigo. $\mathrm{O}$ exame rígido advém da difícil tarefa conferida aos árbitros de averiguar se a medida aplicada unilateralmente objetiva genuinamente proteger "preocupações não-econômicas" ou é apenas um pretexto para proteger a indústria nacional.

Tatjana Eres, em análise especificamente focalizada na possibilidade do art. XX do GATT ser utilizado como "porta dos fundos" para os direitos humanos na OMC, opina pela ausência de base jurídica para o uso da OMC como um fórum para implementar o cumprimento dos direitos humanos, ${ }^{27}$ embora em situações práticas as decisões na aplicação do art. XX possam influenciar drasticamente os direitos humanos. Salienta, ainda, que a extensão do mandato da OMC para incorporar os direitos humanos poderia comprometer toda sua credibilidade, bem como desviar sua atenção para dimensões eminentemente políticas da atuação dos Estados, desvirtuando os objetivos da organização.

Embora não seja de forma explícita, a aplicação do art. XX do GATT pode levar a uma resposta para o caso de conflito entre direitos garantidos pelos Acordos da OMC e eventuais direitos humanos alegados como exceção aos Acordos. O órgão de solução

25 PAUWELYN, Joost. The Role of Public International Law in the WTO: How Far Can We Go? American Journal of International Law, 2001. p. 566.

26 Na versão oficial em português: "Artigo XX. EXCEÇÕES GERAIS- Desde que essas medidas não sejam aplicadas de forma a constituir quer um meio de discriminação arbitrária, ou injustificada, entre os países onde existem as mesmas condições, quer uma restrição disfarçada ao comércio internacional, disposição alguma do presente capitulo será interpretada como impedindo a adoção ou aplicação, por qualquer Parte Contratante, das medidas: (a) necessárias à proteção da moralidade pública; (b) necessárias à proteção da saúde e da vida das pessoas e dos animais e à preservação dos vegetais; (...)"

27 ERES, Tatjana. The Limits of GATT Article XX: a Back Door for Human Rights? Georgetown Journal of International Law, Spring 2004. p. 5. 
de controvérsias tem aplicado o "teste de balanceamento" em diversas circunstâncias, ${ }^{28}$ incluindo a análise (1) da importância dos interesses ou valores que a medida entendida como contrária aos Acordos pretende proteger; (2) a extensão na qual a medida contribui para a realização do fim perseguido e (3) o impacto comercial da medida em questão. Em última instância, há um indireto e complexo balanceamento entre "preocupações nãocomerciais" que podem abranger direitos humanos, e regras do comércio internacional.

Nos últimos anos, seja através das contínuas negociações, que são traço característico da organização, ou através da aplicação dos Acordos da OMC às disputas comerciais pelo sistema de solução de controvérsias, pode-se destacar três principais eixos nos quais aparentes dualismos entre questões específicas de direitos humanos são paulatinamente abandonados: (1) os direitos trabalhistas e o "dumping social"; (2) a saúde pública e os direitos de propriedade intelectual e (3) a proteção ao meio ambiente e o comércio internacional.

\subsection{Os direitos trabalhistas e o "dumping social"}

A Declaração Universal dos Direitos Humanos contém em seus arts. XXIII e XXIV direitos trabalhistas básicos, previstos também na parte III do Pacto Internacional de Direitos Econômicos, Sociais e Culturais, bem como em diversos outros instrumentos internacionais de proteção aos direitos humanos. Embora exista a Organização Internacional do Trabalho (OIT), agência especializada da ONU que busca a promoção da justiça social e o reconhecimento internacional dos direitos trabalhistas, há por parte dos países desenvolvidos grande interesse na inclusão do tema na OMC, através de uma "cláusula social"

A "cláusula social" seria a previsão de direitos trabalhistas mínimos a serem respeitados pelos membros da $\mathrm{OMC}$, como forma de evitar práticas comerciais desleais resultantes de seu descumprimento. O denominado "dumping social" consiste na acusação de que a vantagem econômica resultante do baixo custo da mão-de-obra em países em desenvolvimento decorre da inobservância de regras básicas do direito internacional de proteção do trabalhador, desarmonizando o sistema internacional.

Os Estados em desenvolvimento, entretanto, persistem no entendimento de que a inclusão de cláusula social consiste em intenções protecionistas dos Estados desenvolvidos, visando minar suas vantagens comparativas, motivo pelo qual insistem que os direitos trabalhistas sejam deixados para OIT e demais instituições de direitos

${ }_{28}$ Korea--Various Measures on Beef ("Korea Beef"). Documentos disponíveis em: <http://www.wto.org/ english/tratop_e/dispu_e/cases_e/ds161_e.htm> e US--Measures Affecting the Cross-Border Supply of Gambling and Betting Services ("US Gambling"). Documentos disponiveis em: <http://www.wto.org/ english/tratop_e/dispu_e/cases_e/ds285_e.htm>. 
humanos da ONU. O tema encontra-se, portanto, ainda sob discussão e é um dos principais impasses entre os Estados desenvolvidos e os não desenvolvidos.

Alguns autores destacam que a Carta de Havana constitutiva da Organização Internacional do Comércio, entidade predecessora da OMC que nunca chegou a entrar em funcionamento, já previa em seu texto standards trabalhistas, motivo pelo qual a OMC não poderia abster-se da temática. Entretanto, o texto da Carta de Havana explicita que as partes negociadoras estavam primariamente preocupadas com o efeito de baixos níveis de proteção trabalhista na compettividade do comércio internacional, não havendo a intenção de uma abordagem do comércio internacional baseada nos direitos humanos. ${ }^{29}$

\subsection{A saúde pública e os direitos de propriedade intelectual}

A inclusão do TRIPS (Acordo sobre Aspectos dos Direitos de Propriedade Intelectual Relacionados ao Comércio) no contexto dos Acordos da OMC, deve ser entendida como estratégia dos países desenvolvidos para forçar a criação de leis com padrões mínimos de proteção à propriedade intelectual em países em desenvolvimento. Assim, tendo em vista a peculiariedade da regra do single undertaking, pela qual os membros da OMC não podem escolher os Acordos que desejam aderir, mas somente aceitar o conjunto completo dos Acordos para obter os benefícios como a regra da nação mais favorecida e o direito de acessar o sistema de solução de controvérsias, os Estados devem aceitar o TRIPS, e concordar em implementar padrões mínimos de proteção à propriedade intelectual em suas legislações domésticas.

Sharon Foster salienta que há um aparente conflito entre os direitos humanos à sáude, alimentação e educação, e o também direito humano à proteção moral e material das criações pelos autores e inventores, ambos previstos em instrumentos como a Declaração Universal dos Direitos Humanos e o Pacto Internacional dos Direitos Econômicos, Sociais e Culturais. ${ }^{30}$ Assim, a autora propõe que haja também um "teste de balanceamento" na aplicação das regras do TRIPS, de modo a garantir a efetividade dos direitos humanos que de forma mais crucial protegem a vida e a integridade dos indivíduos.

Nesse contexto, a proteção econômica de fórmulas químicas através de patentes resultou em diminuição do acesso a medicamentos pela população de Estados em desenvolvimento, em violação ao direito à saúde desses indivíduos. Sobre a temática, e após grande pressão dos Estados em desenvolvimento e menos desenvolvidos, foi aprovada

29 ERES, Tatjana. The Limits of GATT Article XX: a Back Door for Human Rights? Georgetown Journal of International Law, Spring 2004. p. 7.

30 FOSTER, Sharon. Prelude to Compatibility between Human Rights and Intellectual Property. Chicago Journal of International Law, Summer 2008. 
em 2001 a Declaração de Doha sobre o TRIPS e a Saúde Pública. ${ }^{31}$ Através da Declaração os membros reconhecem a gravidade de problemas de saúde pública que afetam os Estados em desenvolvimento e menos desenvolvidos, e concordam que o TRIPS deve ser interpretado e implementado de forma a apoiar o direito dos membros de proteger a saúde pública e promover o acesso a medicamentos, inclusive através de mecanismos de flexibilização do Acordo. ${ }^{32}$

A Declaração de Doha de 2001 é entendida por grande parte dos autores supracitados como um exemplo de aplicação dos Acordos da OMC de forma coerente, levando em consideração direitos humanos potencialmente relevantes e, portanto, um avanço na direção de um direito da OMC menos isolado de preocupações humanistas. Assim, se o direito humano à saúde é o "contexto jurídico relevante" para aplicação do TRIPs, também outros direitos humanos podem e devem ser contabilizados no balanceamento de interesses perante o sistema de solução de controvérsias.

\subsection{A proteção ao meio ambiente e o comércio internacional}

Vera Thorstensen destaca que as discussões sobre meio ambiente e comércio internacional se iniciam com a Conferência do Rio sobre Meio Ambiente e Desenvolvimento (ECO 92), quando foi consagrado o conceito de desenvolvimento sustentável, considerado hoje substrato comum para quaisquer negociações na temática ${ }^{33}$ A preocupação com o tema continua atual e relevantíssima, haja vista as negociações objetivando um novo acordo para redução de emissão de gases de efeito estufa.

OAcordo de Marraqueche, que constitui a OMC, explicita em seu preâmbulo a necessidade do uso dos recursos em consonância com o desenvolvimento sustentável, bem como a busca pela proteção e preservação do meio ambiente. Os membros da organização reconhecem, entretanto, que a OMC não é uma agência de proteção ambiental, nem objetiva ser, sendo da sua competência a relação entre comércio e meio ambiente limitada a políticas comerciais e aspectos comerciais de políticas ambientais que tenham efeito significativo sob o comércio. ${ }^{34}$ Foi criado em 1995 o Comitê sobre Comércio e Meio Ambiente, fórum permanente para o diálogo entre governos sobre as relações entre políticas comerciais e meio ambiente.

31 Declaração de Doha sobre o TRIPS e a Saúde Pública, 2001. Disponível em: <http://www.wto.org/english/ theWTO_e/minist_e/min01_e/mindecl_trips_e.htm>

32 BASSO, Maristela. Propriedade Intelectual na Era Pós-OMC. Porto Alegre: Livraria do Advogado, 2005.

33 THORSTENSEN, Vera. OMC-Organização Mundial do Comércio: As Regras do Comércio Internacional e a Nova Rodada de Negociações Multilaterais. São Paulo: Aduaneiras, 2001. p. 288 e ss.

34 Word Trade Organization - Trade and Development Division. Trade and Development on the WTO. 2008. p. 6 . 
$\mathrm{Na}$ aplicação do direito da OMC, diversas foram as situações apresentadas ao sistema de soluções de controvérsias, nas quais medidas de proteção ao meio ambiente resultaram em efeitos discriminatórios e protecionistas ao comércio internacional. Como destacado supra, nessas circunstâncias fáticas há uma análise estrita feita pelos árbitros, através do rigoroso "teste de balanceamento" para que a medida aplicada unilateralmente se configure como exceção prevista pelo art. XX (b) do GATT.

O recente caso das restrições à importação de pneus reformulados, no qual o Brasil foi demandado por iniciativa da União Européia, merece destaque, pois o sistema de solução de controvérsias reconheceu a legitimidade de motivações ambientais como justificativa para limitações ao comércio internacional. Embora já existissem casos na jurisprudência do sistema de solução de controvérsias GATT-OMC em que foram alegadas motivações ambientais para o descumprimento de normas do comércio internacional, tais como os casos United States-Proibition of Imports of Tuna and Tuna Produts from Canada (1988), United States- Restrictions on Imports of Tuna (1992)- The Tuna-dolphin case, United States-Standards for Reformulated and Conventional Gasoline (1996), United States- Import Prohibition on Certain Shrimp and Shrimp Products (1998) e European Communities-Asbestos (2001), a comunidade acadêmica internacional festeja a grande evolução no tratamento da questão ambiental a partir do caso em tela, principalmente por ser a primeira vez em que a exceção do Art. XX (b) foi alegada e reconhecida como legítima em relação a um país em desenvolvimento.

Salienta-se que o direito a um meio ambiente equilibrado é um direito humano por excelência, ${ }^{35}$ enunciado internacionalmente pela primeira vez na Declaração de Estocolmo sobre o Meio Ambiente de 1972, ${ }^{36}$ embora não tenha reconhecimento explícito em instrumentos universais obrigatórios de proteção aos direitos humanos. Assim, quando o sistema de solução de controvérsias da OMC reconhece medidas de proteção ambiental como legítimas ao estabelecimento de medidas restritivas ao comércio, há uma interpretação dos Acordos da OMC que coteja o respeito aos direitos humanos.

\section{Transparência e governança democrática na $\mathrm{OMC}$}

Uma crítica persistente feita à $\mathrm{OMC}$ se refere ao caráter pouco transparente e não democrático de seus processos de tomada de decisão. Alega-se, ademais, que a arquitetura institucional da organização contrasta com princípios de direitos humanos,

\footnotetext{
35 Human rights and the Environment: Final Report, Doc. ONU E/CN.4/Sub. 2/1994/9, 6 de Julho de 1994. Disponivel $\mathrm{em}:<$ http://www.unhchr.ch/Huridocda/Huridoca.nsf/0/eeab2b6937bccaa18025675c005779c3?Opendocument $>$.

36 Declaração de Estocolmo sobre o Meio Ambiente Humano, 1972. Disponível em: <http://www.unep.org/ Documents.Multilingual/Default.asp?DocumentID=97\&ArticleID=1503>
} 
como o direito dos indivíduos de participar do governo em seus Estados, explicitado no art. 21 da Declaração Universal dos Direitos Humanos.

Embora seja possível a participação ad hoc de ONGs, não há previsão para uma participação institucionalizada. Ademais, a inclusão de grupos que defendem interesses comerciais privados na lista de ONGs acreditadas pode promover uma participação desbalanceada, preocupante na perspectiva de direitos humanos, haja vista que a possibilidade de recursos em lobby para que os governos adotem opções de políticas comerciais que promovam determinados interesses privados, em prejuízo do interesse público geral.

Além disso, ainda há falta de transparência na estrutura interna da OMC. Embora seja uma organização teoricamente democrática, pois cada Estado possui direito a um voto, na prática são diversas as dificuldades dos Estados em desenvolvimento para participação igualitária. Há uma inegável diferença de capacidade técnica entre os Estados, ligada também à falta de condições de manter representantes permanentes em Genebra, que se traduzem na dinâmica das negociações em concessões desvantajosas constantemente feitas em favor dos Estados desenvolvidos.

Observa-se certa mudança na situação nos últimos anos, após o posicionamento conjunto dos países em desenvolvimento, inclusive liderados pelo Brasil, na Conferencia Ministerial de Cancun, de recusa em concluir um acordo que não leve em consideração também seus interesses, explicitando potencial força do posicionamento em bloco. Entretanto, o paradoxo aparece no fato de que, na medida em que os países em desenvolvimento alcançam participação mais significativa na OMC, passam a ser acusados de bloquear o sistema. Consequentemente, a tomada de decisões na OMC se afasta de Genebra, para se dar em reuniões não oficiais, também chamadas "miniministeriais", para as quais somente Estados "selecionados" são convidados. Tal "seleção" reduz drasticamente ou ignora a participação dos demais Estados que não se incluem no grupo de convidados, sobrando aos excluídos o posterior aceite de pacotes de regras já negociadas pelo seleto grupo, forçado através de pressões políticas e econômicas às quais acabam por sucumbir.

Nesse contexto, a ausência de transparência, de participação e de democracia na OMC são claramente contrárias aos princípios de direitos humanos que urgem por participação, proteção dos mais vulneráveis e accountability. De forma análoga, a falta de um ambiente democrático na OMC facilita a adoção de regras que deixem de lado preocupações com o interesse público e conflitem com o direito a uma ordem internacional e social na qual os direitos humanos sejam completamente realizados. 


\section{Conclusão}

A relação entre os direitos humanos e a Organização Mundial do Comércio é tema capaz de suscitar intensos debates, como pôde ser observado. Entretanto, embora seja uma equação de difícil resposta, deve ser buscado um equilíbrio entre a liberdade inerente ao comércio, e a proteção, historicamente necessária para a garantia e implementação dos direitos fundamentais.

O contexto de fragmentação do Direito Internacional traz, cada vez mais, a especialização dos ramos do Direito Internacional, sua compartimentalização e a distância entre os específicos conjuntos de regras e princípios. É clara a urgente necessidade de Cortes e Tribunais Internacionais levarem em consideração as outras áreas e regras do Direito internacional em suas decisões, sob pena de emitirem decisões conflitantes entre si e ineficazes concretamente.

Nessa sistemática, o Órgão de Solução de Controvérsias da OMC tem papel fundamental, por se constituir na atualidade como um dos sistemas decisórios mais legítimos e neutros do Direito Internacional, pois baseado em uma análise técnica. Entretanto, exatamente pelo tecnicismo da análise feita pelos panelistas, oportuna seria a negociação em outros órgãos da OMC que autorize explicitamente uma interpretação ponderada das regras, a exemplo da Declaração de Doha sobre TRIPS e saúde pública.

Assim, tendo em vista a complementariedade entre direitos humanos, democracia, meio ambiente e desenvolvimento econômico, observamos que uma interpretação conforme do sistema de normas do comércio internacional se faz necessária para a instrumentalização da OMC de modo a garantir o bem-estar geral, a prescindir de interesses de grupos particulares.

Por todo o exposto, concluímos ser a relação entre direitos humanos e a Organização Mundial do Comércio não somente uma relação possível, mas uma relação necessária, com vistas ao desenvolvimento consistente dos Estados, dos indivíduos e do Direito Internacional. E, para tanto, deve haver uma troca e compartilhamento de perspectivas entre o ramo dos direitos humanos e do comércio internacional, em busca de mútuo entendimento e coerência no Direito Internacional.

São Paulo, agosto de 2010.

\section{Referências}

ALSTON, Philip. Resisting the merger and acquisition of human rights by trade law: a reply to Petersmann. European Journal of International Law, set. 2002.

BASSO, Maristela. Propriedade intelectual na era pós-OMC. Porto Alegre: Livraria do Advogado, 2005 . 
ERES, Tatjana. The limits of GATT Article XX: a back door for human rights? Georgetown Journal of International Law, Spring 2004.

FOSTER, Sharon. Prelude to compatibility between human rights and intellectual property. Chicago Journal of International Law, Summer 2008.

HOWSE, Robert. Human rights in the WTO: whose rights, what humanity? Comment on Petersmann. European Journal of International Law, jun. 2002.

KOSKENNIEMI, Marti. International Law Comission, 58 a sessão. Fragmentation of international law: difficulties arrising from the diversification and expansion of international law. Relatório do estudo analítico realizado pelo Grupo de Estudos da Comissão de Direito Internacional, 13 de abril de 2006, UN. Doc. A/CN.4/L.682. Disponível em: <http://untreaty.un.org/ilc/texts/1_9.htm>.

MARCEAU, Gabrielle. WTO dispute settlement and human rights. European Journal of International Law, set. 2002.

PAUWELYN, Joost. The role of public international law in the WTO: How far can we go? American Journal of International Law, 2001.

PETERSMANN, Ernst-Ulrich. Time for a United Nations 'Global Compact' for Integrating Human Rights into the Law of Worldwide Organizations: Lessons from European Integration. European Journal of International Law, June 2002.

PETERSMANN, Ernst-Ulrich. Reforming the World Trading System: Legitimacy, Efficiency and Democratic Governance. New York: Oxford University Press.

SIMMA, Bruno. PULKOWSKI, Dirk. Of planets and the universe: self-contained regimes in international law. European Journal of International Law, v. 17, n. 3, 2006.

THORSTENSEN, Vera. OMC- Organização Mundial do Comércio: as regras do comércio internacional e a nova rodada de negociações multilaterais. São Paulo: Aduaneiras, 2001.

ZAGEL, Gudrun Monika. WTO \& Human Rights: Examining Linkages and Suggesting Convergence. IDLO Voices of Development Jurists Paper Series, International Development Law Organization. v. 2. n. 2, 2005. Disponível em: <http://www.worldtradelaw.net/articles/zagelhumanrights.pdf>.

Word Trade Organization - Trade and Development Division. Trade and Development on the WTO. 2008 .

\section{Documentos}

Analytical Study of the High Commissioner for Human Rights on the Fundamental Principle of NonDiscrimination in the Context of Globalization, E/CN.4/2004/40, 15 de Janeiro de 2004. Disponivel em: $<$ http://www.unhchr.ch/Huridocda/Huridoca.nsf/(Symbol)/E.CN.4.2004.40.En?Opendocument>.

Declaração de Doha sobre o TRIPS e a Saúde Pública, 2001. Disponível em: <http://www.wto.org/ english/theWTO_e/minist_e/min01_e/mindecl_trips_e.htm> 
Declaração de Estocolmo sobre o Meio Ambiente Humano, 1972. Disponível em: <http://www. unep.org/Documents.Multilingual/Default.asp?DocumentID=97\&ArticleID=1503>.

Declaração de Viena sobre os Direitos Humanos, 1993. Disponível em: <http://www.unhchr.ch/ huridocda/huridoca.nsf/(symbol)/A.CONF.157.23.En?OpenDocument>

Human Development Report 2000: Human Rights and Human Development, Programa das Nações Unidas Para o Desenvolvimento - UNDP. Disponível em: <http:/hdr.undp.org/en/media/ HDR_2000_EN.pdf>

Human rights and the Environment: Final Report, Cf. Doc. ONU E/CN.4/Sub. 2/1994/9, 6 de Julho de 1994. Disponível em: <http://www.unhchr.ch/Huridocda/Huridoca.nsf/0/eeab2b6937bccaa18025675c 005779 c3?Opendocument>

Human Rights, Trade and Investment, E/CN.4/Sub.2/2003/9, 18 de Junho de 2003. Disponível em: $<$ http://www.unhchr.ch/Huridocda/Huridoca.nsf/0/32f8a4ad6cc5f9b9c1256c05002a87f8? Opendocument>.

Globalization and its Impact on the Full Enjoyment of Human Rights, E/CN.4/Sub.2/2000/13, 15 de Junho de 2000. Disponível em: <http://www.unhchr.ch/Huridocda/Huridoca.nsf/(Symbol)/E. Cn.4.Sub.2.2000.13.En?Opendocument>.

Globalization and its Impact on the Full Enjoyment of Human Rights, E/CN.4/2002/54, 15 de Janeiro de 2002. Disponível em: <http://www.unhchr.ch/huridocda/huridoca.nsf/(Symbol)/E. CN.4.2002.54.En?Opendocument>.

Globalization and its Impact on the Full Enjoyment of Human Rights: Final Report, E/CN.4/ Sub.2/2003/14, 25 de Junho de 2003. Disponível em: <http://www.unhchr.ch/Huridocda/Huridoca.nsf/ (Symbol)/E.CN.4.Sub.2.2003.14.En?Opendocument>.

Liberalization of Trade in Services and Human Rights, E/CN.4/Sub.2/2002/9, 18 de Junho de 2002. Disponivel em: <http://www.unhchr.ch/Huridocda/Huridoca.nsf/0/32f8a4ad6cc5f9b9c1256c 05002a87f8? Opendocument>.

Mainstreaming the right to development into international trade low and policy at the World Trade Organization, E/CN.4/Sub.2/2004/17, 9 de Junho de 2004. Disponível em: <http://daccess-dds-ny. un.org/doc/UNDOC/GEN/G04/145/22/PDF/G0414522.pdf?OpenElement>.

Órgão de Solução de Controvérsias da OMC, Korea--Various Measures on Beef ("Korea Beef"), documentos. Disponíveis em: <http://www.wto.org/english/tratop_e/dispu_e/cases_e/ds161_e. htm>.

Órgão de Solução de Controvérsias da OMC, US--Measures Affecting the Cross-Border Supply of Gambling and Betting Services ("US Gambling"). Disponiveis em: <http://www.wto.org/english/ tratop_e/dispu_e/cases_e/ds285_e.htm>.

Report by the Special rapporteur Paul Hunt on his Mission to the WTO, E/CN.4/2004/49/Add.1, 1 de Março de 2004. Disponível em: <http://www.unhchr.ch/Huridocda/Huridoca.nsf/0/893elcddedb9014cc12 56e670046d0fa/\$FILE/G0411393.doc >. 
The impact of the Agreement on Trade-Related Aspects of Intellectual Property Rights on Human Rights, E/CN.4/Sub.2/2001/13, 27 de Junho de 2001. Disponível em: <http://www.unhchr.ch/ Huridocda/Huridoca.nsf/Symbol/E.CN.4.Sub.2.2001.13.En?Opendocument>. 